Correction

\title{
Correction: Castellini, M., et al. Spatial Variability of Soil Physical and Hydraulic Properties in a Durum Wheat Field: An Assessment by the BEST-Procedure. Water 2019, 11, 1434
}

\author{
Mirko Castellini ${ }^{1, *(D)}$, Anna Maria Stellacci ${ }^{2}$, Matteo Tomaiuolo ${ }^{3}$ and Emanuele Barca $^{4}$ (D) \\ 1 Council for Agricultural Research and Economics-Research Center for Agriculture and \\ Environment (CREA-AA), Via C. Ulpiani 5, 70125 Bari, Italy \\ 2 Department of Soil, Plant and Food Sciences, University of Bari “Aldo Moro", Via G. Amendola 165/a, \\ 70126 Bari, Italy; annamaria.stellacci@uniba.it \\ 3 Council for Agricultural Research and Economics-Policies and Bioeconomy Research Centre (CREA-PB), \\ Via C. Ulpiani 5, 70125 Bari, Italy; matteo.tomaiuolo@crea.gov.it \\ 4 Water Research Institute (IRSA)—National Research Council (CNR), Viale Francesco de Blasio 5, \\ 70132 Bari, Italy; emanuele.barca@ba.irsa.cnr.it \\ * Correspondence: mirko.castellini@crea.gov.it; Tel.: +39-080-5475039
}

Received: 23 September 2019; Accepted: 23 September 2019; Published: 21 October 2019

The authors wish to make the following corrections to this paper [1]:

In the front matter, the authors' names should be "Mirko Castellini 1,*, Anna Maria Stellacci ${ }^{2}$, Matteo Tomaiuolo ${ }^{3}$ and Emanuele Barca ${ }^{4 \prime}$.

The authors would like to apologize for any inconvenience caused to the readers by the change. The change does not affect the scientific results. The manuscript will be updated, and the original will remain online on the article webpage with a reference to this correction.

\section{References}

1. Mirko, C.; Anna, M.S.; Matteo, T.; Emanuele, B. Spatial Variability of Soil Physical and Hydraulic Properties in a Durum Wheat Field: An Assessment by the BEST-Procedure. Water 2019, 11, 1434. [CrossRef]

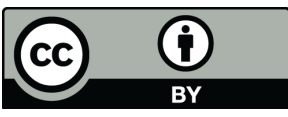

(C) 2019 by the authors. Licensee MDPI, Basel, Switzerland. This article is an open access article distributed under the terms and conditions of the Creative Commons Attribution (CC BY) license (http://creativecommons.org/licenses/by/4.0/). 